\title{
Extended State Observer-Based Sliding Mode Control with New Reaching Law for PMSM Speed Control
}

\author{
Junzhang Qian, ${ }^{1,2}$ Ai Xiong, ${ }^{1}$ and Wenli $\mathrm{Ma}^{1}$ \\ ${ }^{1}$ The Institute of Optics and Electronics, Chinese Academy of Sciences, Chengdu 610209, China \\ ${ }^{2}$ Graduate School of the Chinese Academy of Sciences, Beijing 100039, China \\ Correspondence should be addressed to Junzhang Qian; qianjunzhang12@mails.ucas.ac.cn
}

Received 18 January 2016; Revised 3 May 2016; Accepted 17 May 2016

Academic Editor: Driss Mehdi

Copyright (c) 2016 Junzhang Qian et al. This is an open access article distributed under the Creative Commons Attribution License, which permits unrestricted use, distribution, and reproduction in any medium, provided the original work is properly cited.

\begin{abstract}
In order to improve the performance of external disturbance rejection of permanent magnet synchronous motor (PMSM) in speed control, sliding mode control with extended state observer is adopted in this paper. First, an exponential function-based sliding mode reaching law (ESMRL) is developed. The ESMRL can dynamically adapt to the variations of the controlled system, which decrease the reaching time in reaching stage and void chattering in sliding motion stage while maintaining high tracking accuracy of the servo system. Then, an extended state observer (ESO) is introduced to the controller to simultaneously estimate external disturbance and compensate the uncertainties. Simulation results demonstrate that the proposed method has better suppression of chattering effect and disturbance rejection ability while ensuring dynamic performance.
\end{abstract}

\section{Introduction}

Permanent magnet synchronous motor (PMSM) has many excellent features such as high efficiency, low noise, high power density, and friendly maintenance [1]. Due to these advantages, PMSM has been widely used in the industry such as aviation, vehicles, robotics, and power converters [2]. During the operation of PMSM, the change of load and moment of inertia has great impact on the system performance. High performance servo system requires no overshoot, fast transient response, and no steady-state error and is robust to the change of parameters and disturbance. Conventional control method such as PI control scheme has been widely used for its simple structure and easy implementation. However, in case of parameter variations and unavoidable external disturbances, it is difficult to achieve satisfactory performance with PI control algorithm [3].

Therefore, many scholars concentrate on the robustness of the servo system and have developed lots of nonlinear control methods, for example, active-disturbance rejection controller (ADRC) [4], sliding mode control [5-7], predictive control [8], fuzzy control $[9,10]$, intelligent control [11], backstepping control $[12,13]$, and observer-based control [14].
The sliding mode control has been widely and successfully used in PMSM servo system [15-17] because of its easy implementation, fast response, and robustness for external disturbance and internal parameter variations. Usually, a conventional first-order sliding mode control is used in the design of the servo control system, which would cause chattering phenomenon because of high-frequency switching control. Therefore, the suppression of chattering becomes more and more important in sliding mode control and scholars have focused on the method to counteract the chattering in the past decades. Bound layer was introduced by using a saturation function instead of the switching control around the sliding surface [18]. A disturbance observer was used to compensate the disturbance and significantly avoid the chattering [19]. In [20], second-order or high order sliding mode control was applied to reduce the chattering. In [21], Gao and Hung proposed some reaching laws to reduce or even eliminate chattering. However, the gain rapidly decreases in these reaching laws because of the variation of sliding surface function, which reduces the robustness of the control system near the sliding surface and also increases the reaching time.

In this paper, a sliding mode reaching law based on exponential term function, which adapts to the variations 


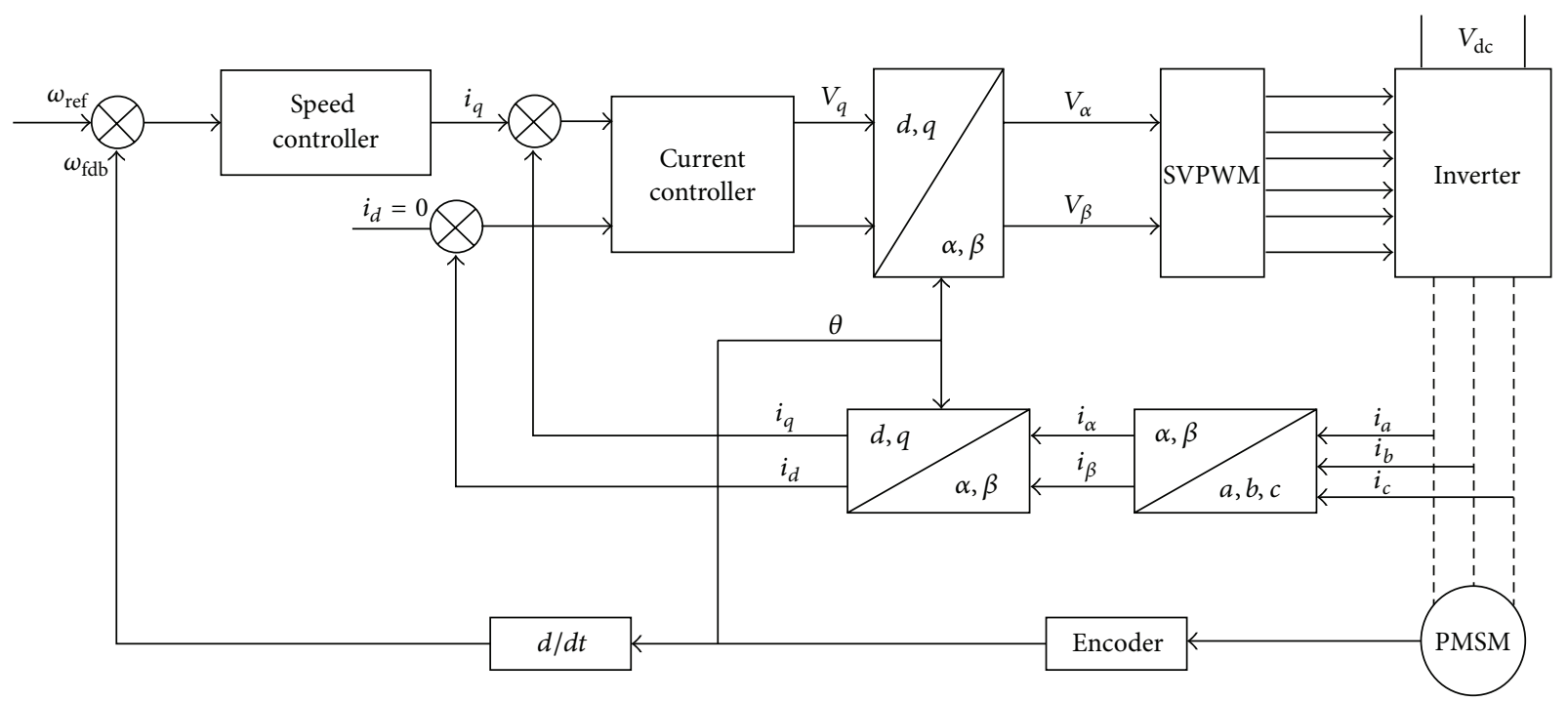

FIGURE 1: The configuration of the speed vector control of PMSM.

of the system states and sliding mode surface, is proposed. Moreover, the reaching law is able to deal with the reaching time/chattering dilemma. Based on the new reaching law, a sliding mode controller for PMSM speed control is developed. Furthermore, in order to improve the disturbance rejection performance of the system, extended state observer (ESO) is adopted to estimate the external disturbance, which is employed for feedforward compensation of the control law. Thus, a composite control strategy combining ESMRL and a feedforward compensation part based on ESO, called ESMRL + ESO strategy, is proposed. The simulation results prove that the proposed scheme has achieved a better performance with shorter settling time, no overshoot, high accuracy, and robustness.

The paper is organized as follows. The model description of the PMSM drive system and some background are given in Section 2. The proposed improved sliding mode reaching law (ESMRL) and its stability analysis are presented in Section 3. Then, an introduction of ESO and ESMRL + ESO strategy is given in Section 4. Finally, simulation results are demonstrated in Section 5 and concluding remarks are given in Section 6.

\section{Preliminary}

2.1. Modeling of PMSM Drive System. The mathematics mode for the permanent magnet synchronous motor in the rotor rotating reference frame $(d-q)$ can be described as follows:

$$
\begin{aligned}
& u_{d}=R_{s} i_{d}+p \psi_{d}-\omega_{r} \psi_{q}, \\
& u_{q}=R_{s} i_{q}+p \psi_{q}+\omega_{r} \psi_{d}, \\
& \psi_{d}=L_{d} i_{d}+\psi_{f d}, \\
& \psi_{q}=L_{q} i_{q},
\end{aligned}
$$

where $u_{d}$ and $u_{q}$ and $i_{d}$ and $i_{q}$ are the $d$ - and $q$-axis voltages (volt) and currents, respectively; $R_{s}$ is the stator resistance; $L_{d}$ and $L_{q}$ are the $d$ - and $q$-axis stator inductances; $\psi_{d}$ and $\psi_{q}$ are the $d$ - and $q$-axis stator flux linkages; $\psi_{f d}$ is the equivalent $d$ axis flux linkage; $\omega_{r}$ is the angular velocity $(\mathrm{rad} / \mathrm{s}) ; p$ is the pole-pairs of motor.

The electromagnetic torque equation is presented as

$$
T_{e}=\frac{3 p\left(\psi_{f} i_{q}+\left(L_{d}-L_{q}\right) i_{d} i_{q}\right)}{2} .
$$

The motor dynamic equation is stated as

$$
T_{e}-T_{L}=J \frac{d \omega}{d t}+B \omega
$$

where $T_{L}$ is the lumped disturbance, $J$ is the moment of inertia, and $B$ is the viscous friction coefficient.

By utilizing the vector control method with $i_{d}=0$ and substituting (2) into (3), the second-order state equation of PMSM motor can be achieved:

$$
\begin{aligned}
& \dot{\theta}=\omega, \\
& \dot{\omega}=\frac{3 p \psi_{f}}{2 J} i_{q}-\frac{B}{J} \omega-\frac{T_{L}}{J} .
\end{aligned}
$$

The structure of the PMSM servo system is presented in Figure 1, which consists of a PMSM, a SVPWM voltage source inverter, an encoder, a current controller, three coordinate translators, and a speed controller. The speed controller will be described in detail in the next part.

2.2. Problem Formulation. The most important advantage of SMC is its insensitivity to external disturbance and internal parameter variations once the system reaches the sliding surface. However, chattering is the major drawback which limits the wide implementation of SMC. A complete study of 
sliding mode reaching laws is presented in [21] that motivates our researches for an improved reaching law which will be introduced in the next section.

In this section, the design method of SMC is briefly introduced. Generally, the design is divided into two steps; the first step is to choose a proper sliding mode surface, and the second step is to design an appropriate control input which forces the system trajectory move on the sliding mode surface.

An SMC system with reaching law is generally described as a second-order nonlinear system as follows:

$$
\begin{aligned}
& \dot{x}_{1}=\dot{x}_{2}, \\
& \dot{x}_{2}=f(x)+b(x) \cdot u,
\end{aligned}
$$

where $x=\left[x_{1}, x_{2}\right]^{T}$ represents the system state, $f(x)$ is the system disturbance, and $b(x)$ is invertible and not zero.

The typical sliding mode surface $s$ is chosen as follows:

$$
s=c x_{1}+x_{2}
$$

The asymptotic stability of the system can be guaranteed by such sliding mode surface, while the convergence rate is directly related to the value of $c$.

After choosing the sliding surface for the sliding stage, the next step is to choose the control law $u$ which will force the trajectory move on the sliding surface. To do so, the control law must satisfy the reaching condition that is described as follows:

$$
s \cdot \dot{s}<0 .
$$

Typically, in order to meet the reaching condition (7), the reaching law is chosen as follows:

$$
\dot{s}=-k \cdot \operatorname{sign}(s) .
$$

Substituting (6) into (8) results in

$$
c \dot{x}_{1}+\dot{x}_{2}=-k \cdot \operatorname{sign}(s) .
$$

Next, substituting (5) into (9) yields

$$
c x_{2}+f(x)+b(x) \cdot u=-k \cdot \operatorname{sign}(s) .
$$

Then, the control input $u$ could be easily obtained as follows according to (10):

$$
u=b^{-1}(x)\left[-c x_{2}-f(x)-k \cdot \operatorname{sign}(s)\right] .
$$

Obviously, the discontinuous term $-b^{-1}(x) \cdot k \cdot \operatorname{sign}(s)$ in the control input will lead to the chattering phenomenon, and chattering level lies on the value of $k$ directly.

From (8), the time required in reaching stage can be derived as follows:

$$
t=\frac{|s(0)|}{k} .
$$

From (12), it can be seen that the reaching speed is also controlled by the value of $k$ directly. The value of $k$ must be increased in order to get a faster reaching speed and a better robustness, but high gain $k$ will lead to the increase of chattering level of the control input. Therefore, an improved reaching law is proposed in order to solve the dilemma in the next section.

\section{Design of SMC Speed \\ Controller with ESMRL}

3.1. The Description of ESMRL. The new ESMRL in the paper is realized based on the choice of an exponential term which adapts to the variation of the system states and sliding mode surface. The reaching law is given by

$$
\begin{aligned}
\dot{s} & =-f(x, s) \cdot \operatorname{sign}(s), \\
f(x, s) & =\frac{k|x|}{\varepsilon+(1-\varepsilon) e^{-\eta|s|}}
\end{aligned}
$$

where $k>0, \eta>0,0<\varepsilon<1$ and $x$ is the system state.

It is obvious that the stability of the system will not be affected because $f(x, s)$ is always strictly positive. In the new reaching law, it can be found that, with the increase of $|s|$, $f(x, s)$ converges to the value of $k|x| / \varepsilon$ which is greater than the value of $k / \varepsilon$. This means that the speed is increased in reaching stage and the attraction to the sliding surface would be faster. On the other hand, if $|s|$ decreases, $f(x, s)$ will converge to $k|x|$. It indicates that when the trajectory approaches the sliding surface, $f(x, s)$ gradually decreases to zero in order to suppress the chattering. Therefore, the proposed reaching law in this paper can dynamically adapt to the variations of the system state $|x|$ and sliding surface $|s|$.

From (13) and (14), it can be obtained that

$$
\dot{s}\left[\varepsilon+(1-\varepsilon) e^{-\eta|s|}\right]=-k|x| \cdot \operatorname{sign}(s) .
$$

Let $t_{1}$ be the reaching time; integrating (15) from zero to $t$ with $s\left(t_{1}\right)=0$ will yield

$$
t_{1}=\frac{1}{k|x|}\left[\varepsilon|s(0)|+\frac{1-\varepsilon}{\eta}\left(1-e^{-\eta|s(0)|}\right)\right] .
$$

Because of $1-e^{-\eta|s(0)|}<1$, the following inequality can be obtained:

$$
t_{1}<\frac{1}{k|x|}\left[\varepsilon|s(0)|+\frac{1-\varepsilon}{\eta}\right] .
$$

From (17) it can be found that if the parameter $\eta$ is properly chosen to satisfy $\eta \gg 1-\varepsilon$, inequality (17) can be simplified as

$$
t_{1}<\frac{\varepsilon|s(0)|}{k|x|}
$$

Hence, according to inequality (18) and equality (12), the relationship between $t$ and $t_{1}$ can be obtained as follows:

$$
t_{1}-t<\frac{\varepsilon|s(0)|}{k|x|}-\frac{|s(0)|}{k}=\frac{|s(0)|}{k}\left(\frac{\varepsilon}{|x|}-1\right) \text {. }
$$

Note that, in the reaching stage $|x| \gg \varepsilon, \varepsilon /|x|-1$ is always negative and $|s(0)| / k$ is strictly positive, implying that $t_{1}-t<$ 0 . It means that the proposed new reaching law has improved the reaching speed in the reaching stage with the same gain $k$.

On the other hand, if the sliding mode surface $s$ is around zero, then $f(x, s)$ will converge to $k|x|$. Hence, the proposed 


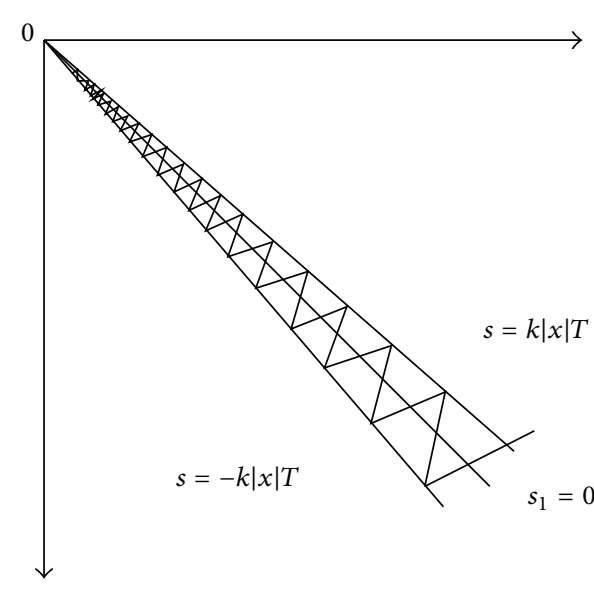

(a)

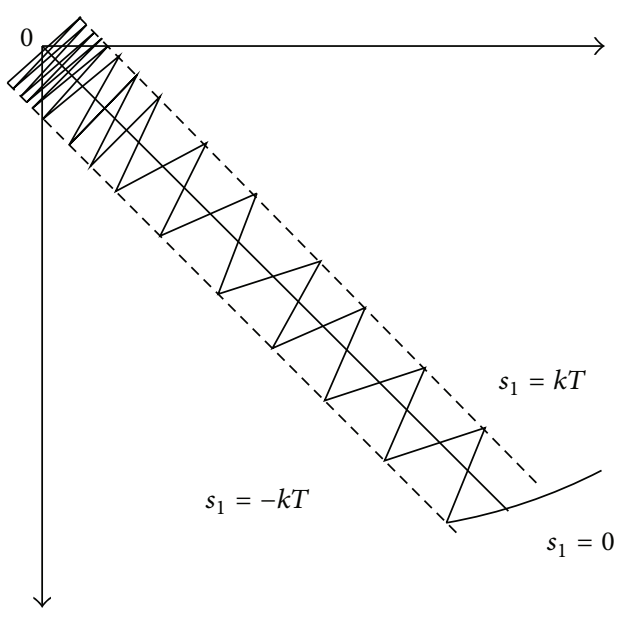

(b)

FIGURE 2: State trajectories of reaching law. (a) Proposed reaching law. (b) Equal rate reaching law.

reaching law in (14) can be simplified as $\dot{s} \approx-k|x| \cdot \operatorname{sign}(s)$. Then, the discrete expression can be obtained as

$$
s(n+1)-s(n) \approx-k|x| T \cdot \operatorname{sign}(s),
$$

where $T$ is the sample period of the system. Assume that the system trajectory reaches the sliding mode surface in a finite time, which means $s(n)=0^{-}$or $s(n)=0^{+}$.

Then, with $s(n)=0^{-}$, the next period equation can be written as follows:

$$
s(n+1)=k|x| T \text {. }
$$

The next period equation with $s(n)=0^{+}$can also be obtained as follows:

$$
s(n+1)=-k|x| T .
$$

Therefore, the sliding mode bandwidth can be acquired as

$$
\Delta=k|x| T
$$

In the same way, the sliding mode bandwidth of (8) can also be written as

$$
\Delta_{1}=k T
$$

Comparing (23) with (24), we will find that the equal rate reaching law has a constant bandwidth, which means that the system state cannot reach the equilibrium point $(0,0)$ with equal rate reaching law. It will chatter in the bandwidth $\Delta_{1}$. On the other hand, the bandwidth of the proposed reaching law will decrease with the decrease of system state $|x|$, which means that the equilibrium point $(0,0)$ will be reached with the proposed reaching law in finite time. Therefore, the chattering phenomenon can be greatly suppressed with the proposed reaching law. The comparison of the state trajectories of two reaching laws is listed in Figure 2.
3.2. Design of Speed Controller Based on ESMRL. In order to accurately track speed reference $\omega_{r}$ under the occurrence of uncertainty, the tracking error is defined as $e=\omega_{r}-\omega$. Then, the sliding mode surface can be chosen as

$$
s=e=\omega_{r}-\omega
$$

Then, taking the derivative of sliding mode surface will yield

$$
\dot{s}=\dot{\omega}_{r}-\dot{\omega} .
$$

Substituting the new reaching law (13) into (26) yields

$$
\dot{\omega}=\dot{\omega}_{r}+f(x, s) \cdot \operatorname{sign}(s) .
$$

Therefore, the control input $i_{q}$ can be obtained as follows by substituting (4) into (27):

$$
i_{q}=\frac{\left[b \omega+d+\dot{\omega}_{r}+f(x, s) \cdot \operatorname{sign}(s)\right]}{a},
$$

where $a=3 p \psi_{f} / 2 J, b=B / J, d=T_{L} / J$.

As can be seen in (28), the lumped disturbance $d$ is included in the control input. In order to compensate it, the extended state observer (ESO) and ESMRL + ESO strategy will be introduced in the next section.

3.3. Simulation Results. In order to verify the effectiveness of the new reaching law, simulations have been made to compare the new reaching law with equal rate reaching law on the PMSM system. The parameters of PMSM are shown in Table 1, and the results are demonstrated in Figures 3 and 4.

In the simulation, the speed reference is $\omega=500 \mathrm{rpm}$ and the lumped disturbances are ignored. The switching gain of the equal rate reaching law is $k=5$, while the parameters of the new reaching law are $k=5, \eta=2, \varepsilon=0.2$, and $x=e$. The simulation results of the sliding surface are listed in Figure 3, and the results of $q$-axes current are shown in 


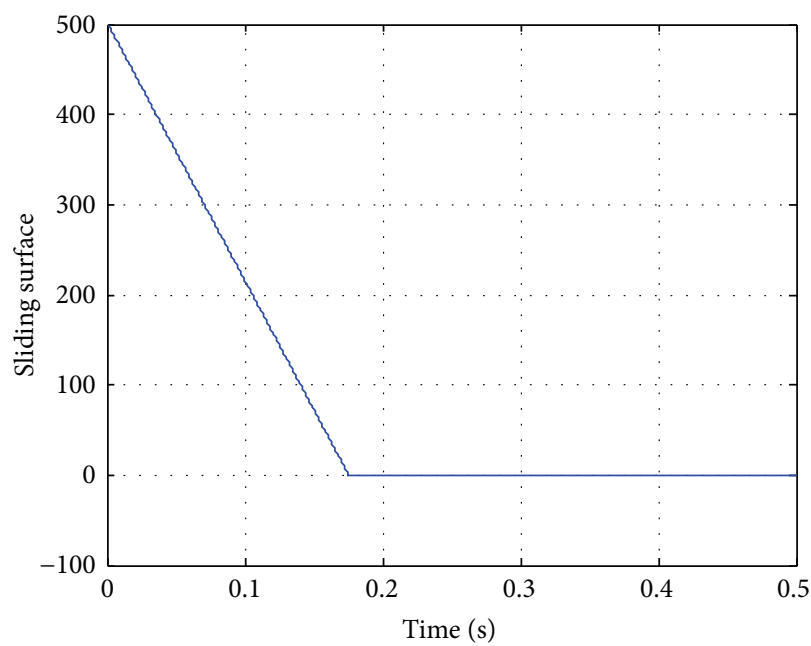

(a)

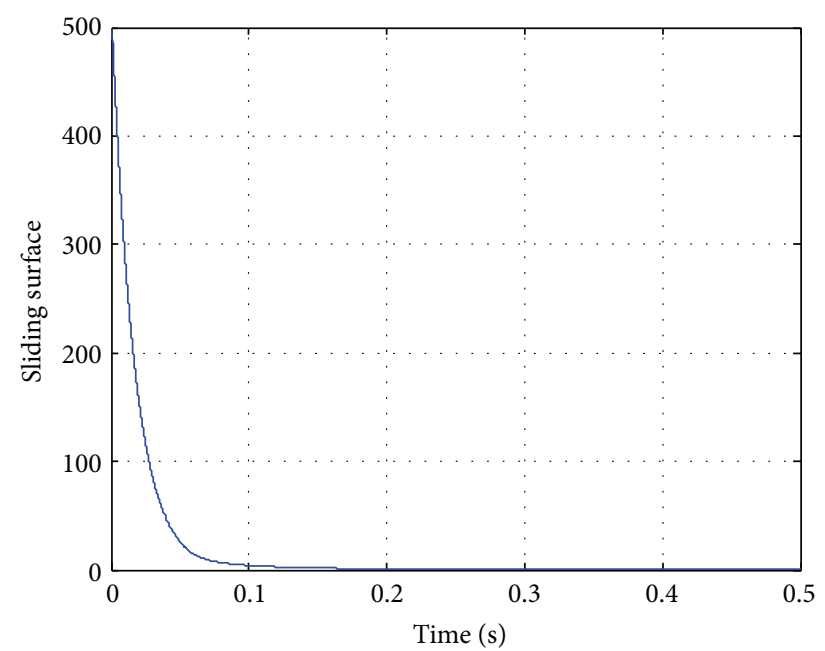

(b)

FIGURE 3: Simulation result of sliding surface: (a) under equal rate reaching law; (b) under proposed reaching law.

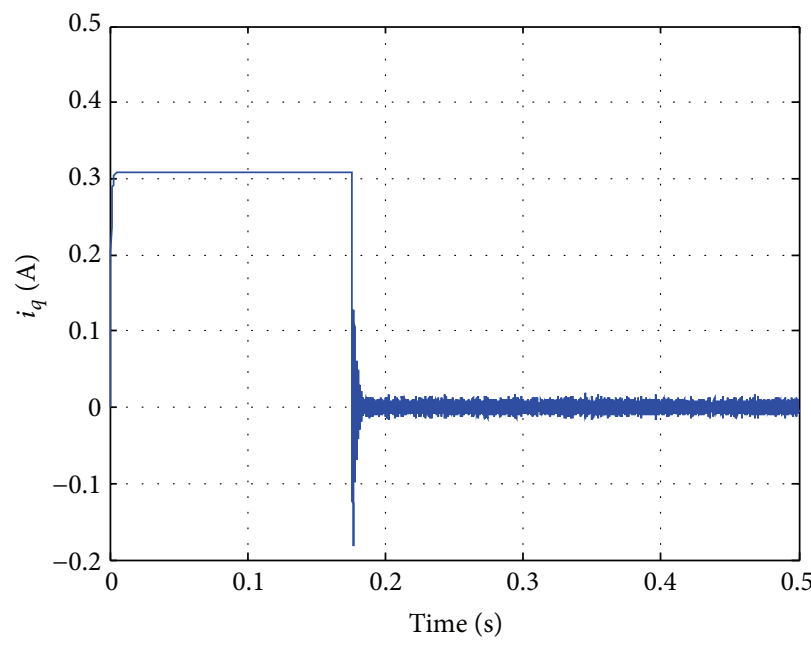

(a)

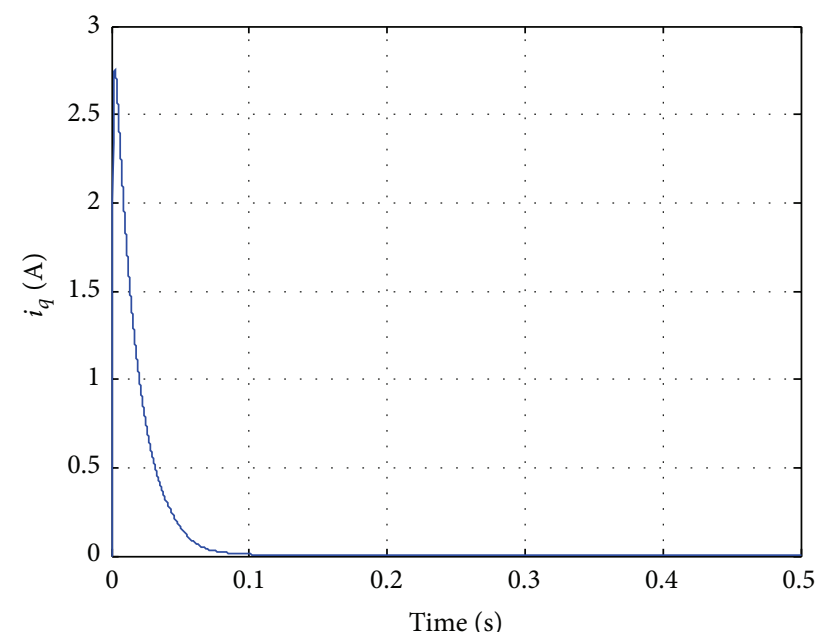

(b)

FIGURE 4: Simulation result of $q$-axes current: (a) under equal rate reaching law; (b) under proposed reaching law.

TABLE 1: The parameters of PMSM.

\begin{tabular}{lc}
\hline Features & Values \\
\hline$R_{s}$ (resistance) & $0.37 \mathrm{ohm}$ \\
$L(q$-axis inductance) & $4.2 \mathrm{mH}$ \\
$J_{m}$ (motor inertia) & $1.23 \mathrm{~kg} \cdot \mathrm{m}^{2}$ \\
$K_{t}$ (torque constant) & $20.0023 \mathrm{Nm}$ \\
$B_{m}$ (friction coefficient) & $0.003035 \mathrm{Nm} \cdot \mathrm{s}$ \\
$p_{n}$ (number of poles) & 28 \\
$S_{r}$ (rated speed) & $375 \mathrm{rpm}$ \\
$T_{r}$ (rated torque) & $764 \mathrm{Nm}$ \\
\hline
\end{tabular}

Figure 4. From the results, it can be found that the proposed new reaching law not only increases the reaching speed in reaching stage but also greatly improves the chattering level of the control input compared with equal rate reaching law.

\section{ESO-Based Composite Control Strategy}

4.1. ESO-Based Controller for PMSM. The lumped disturbances of the PMSM system include external disturbance, for example, variation of friction load torque, and internal disturbances, for example, variations of parameters and unmodeled dynamics [22]. These disturbances will degrade the control performance unless a corresponding feedforward compensation technique is considered to suppress it. In order to solve this, the estimation of disturbances should be obtained. ESO is a conventional state observer that not only observes the system state but also estimates the lumped disturbance by considering it as an extended state. Then, the 


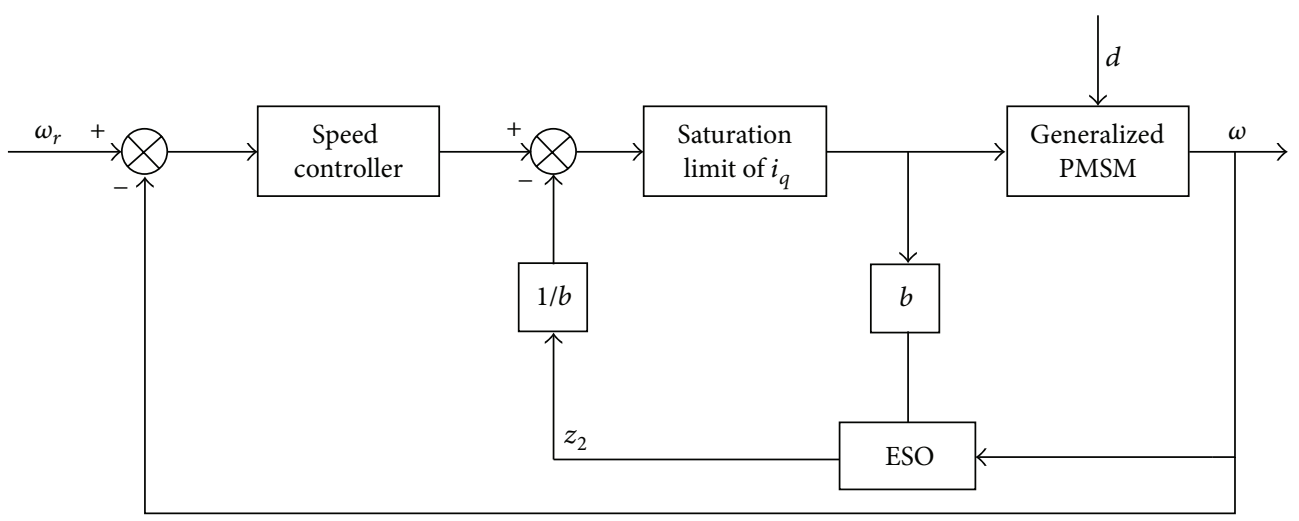

FIgURE 5: The block diagram of ESO-based control.

estimated lumped disturbances are used as a feedforward part to the control law to compensate the lumped disturbances as shown in Figure 5.

From (4) and according to [23], a linear ESO can be constructed as follows:

$$
\begin{aligned}
& \dot{z}_{1}=z_{2}-2 p\left(z_{1}-\omega\right)+\frac{3 p \psi_{f}}{2 J} i_{q}, \\
& \dot{z}_{2}=-p^{2}\left(z_{1}-\omega\right),
\end{aligned}
$$

where $z_{1}$ is the estimation of speed $\omega, z_{2}$ is the estimation of the lumped disturbance, and $-p$ is the desired double pole of ESO with $p>0$.

Therefore, the composite control law based on ESMRL + ESO can be written as

$$
i_{q}=\frac{\left[b \omega+\dot{\omega}_{r}-z_{2}+f(x, s) \cdot \operatorname{sign}(s)\right]}{a} .
$$

By using this strategy, the disturbance could be estimated and compensated online which will greatly improve the tracking accuracy and robustness of the system.

In order to meet the reaching condition, the Lyapunov function is chosen as

$$
V=\frac{s^{2}}{2} .
$$

Deriving (31) and substituting (4), (26), and (30) into it will yield

$$
\begin{aligned}
\dot{V} & =s \cdot \dot{s}=s \cdot\left(\dot{\omega}_{r}+b \omega+d-a \cdot i_{q}\right) \\
& =s \cdot[-f(x, s) \cdot \operatorname{sign}(s)]=-|s| \cdot f(x, s) \leq 0 .
\end{aligned}
$$

So, the composite control strategy makes the system stable and sliding surface will converge to zero in finite time.

\section{Simulation Results}

Simulations are implemented to verify the performance of ESO in the estimation of disturbance and to demonstrate the tracking performance based on ESMRL + ESO strategy. The parameters of PMSM are listed in Table 1, and the simulations are established in MATLAB/Simulink. All the parameters of current loop are the same: the proportional gain $k_{p}=5.27$ and the integral gain $k_{i}=465$. The speed loop parameters of PI controller are proportional gain $k_{p s}=0.5$ and integral gain $k_{i s}=3$. The speed loop parameters of ESMRL + ESO are $k=5, \eta=2, \varepsilon=0.2$, and $p=150$.

First of all, a comparison of step response with speed reference $\omega=500 \mathrm{rpm}$ is carried out between ESMRL + ESO control strategy, traditional SMC controller, and PI controller. The speed response is illustrated in Figure 6. It is obvious that the performance of the ESMRL + ESO control strategy is much better than traditional SMC controller and PI controller, with smaller rising time and settling time. A large overshoot of almost $16 \%$ is obtained by PI controller which is unacceptable. To further test the tracking performance of the system in wide speed range, a square wave with $500 \pm 200 \mathrm{rpm}$ is applied to the system and the response is demonstrated in Figure 7. The figure verifies that the system with ESMRL + ESO control strategy has a better tracking ability than that with traditional SMC controller and PI controller. In order to test the rejection ability of system, a comparison of ESMRL + ESO control strategy with SMC controller, PI controller, and ESMRL controller is made and the external disturbance $T_{L}=1 \mathrm{~N} \cdot \mathrm{m}$ is suddenly added into the system at $t=0.8 \mathrm{~s}$ and removed at $t=1.5 \mathrm{~s}$. The simulation results are shown in Figure 8. It can be seen that the ESMRL + ESO controller has less fluctuation of speed with a deviation of $2 \mathrm{rpm}$, while the ESMRL controller and traditional SMC controller have a speed deviation of $4 \mathrm{rpm}$ and $6 \mathrm{rpm}$, respectively. Besides, the chattering phenomena still exist in the traditional SMC controller. The system with PI controller has a peak speed deviation of $18 \mathrm{rpm}$ and recovers in about $0.5 \mathrm{~s}$. The estimated disturbance is demonstrated in Figure 9; it can be found that ESO can exactly estimate the disturbance. On the other hand, Figure 10 displays the step response with different inertia between PI controller, SMC controller, and ESMRL + ESO controller, respectively. It is obvious that the variation of inertial almost has no effect on the system robustness with 


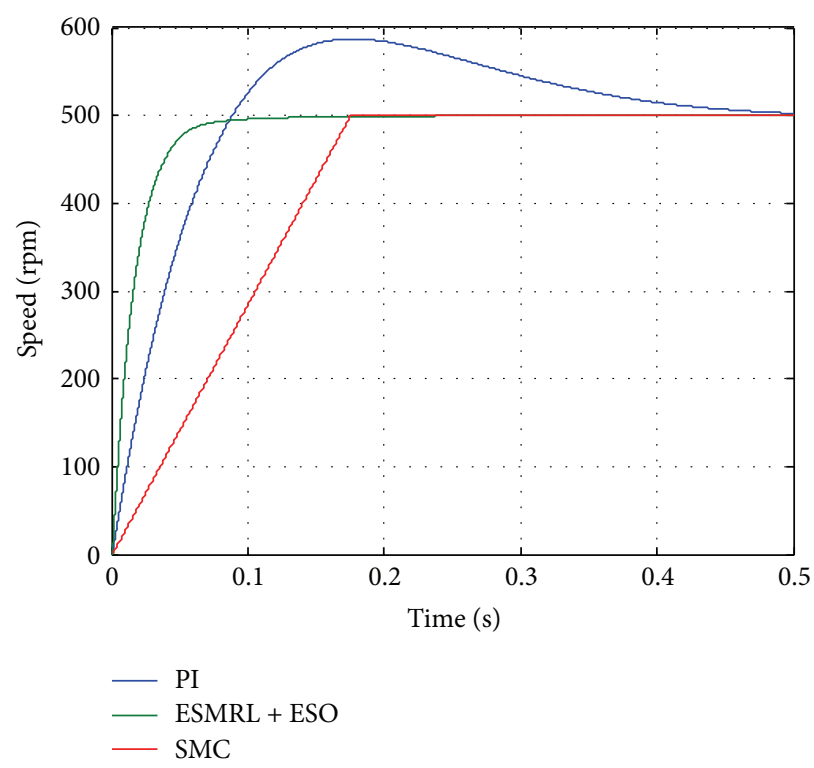

FIGURE 6: Speed response to step command.

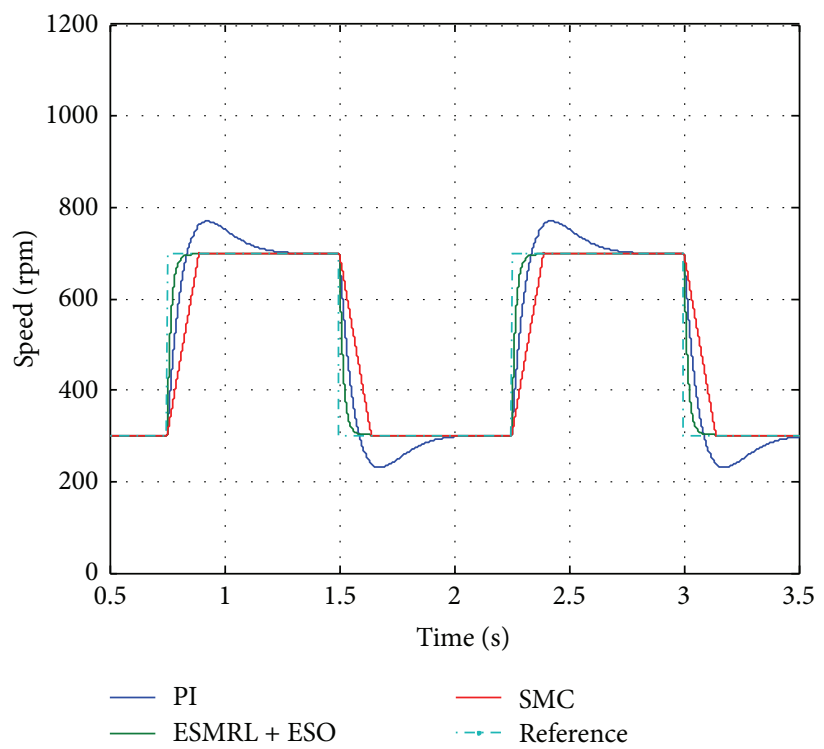

FIGURE 7: Tracking performance of wide speed range.

SMC controller and ESMRL + ESO controller; it just affects the rising time of the system, while response and overshoot with PI controller will be impacted by the variation of inertial, which will affect the stability of the system.

\section{Conclusion}

In this paper, sliding mode control technique has been studied and applied to the speed control of PMSM system. In order to suppress the chattering phenomenon and improve tracking performance, an ESMRL based on exponential term function is proposed. Moreover, extended state observer is implemented to estimate the disturbance and compensate it online. Then, a composite strategy ESMRL + ESO is developed to further improve the tracking performance and disturbance rejection ability. The control stability of the system has been proved by Lyapunov stability theory.

Based on the analyses and simulations, it can be concluded that the proposed controller significantly improved the system performance by ensuring the invariance property against disturbance and parameters, fast transient response, and high tracking accuracy. 


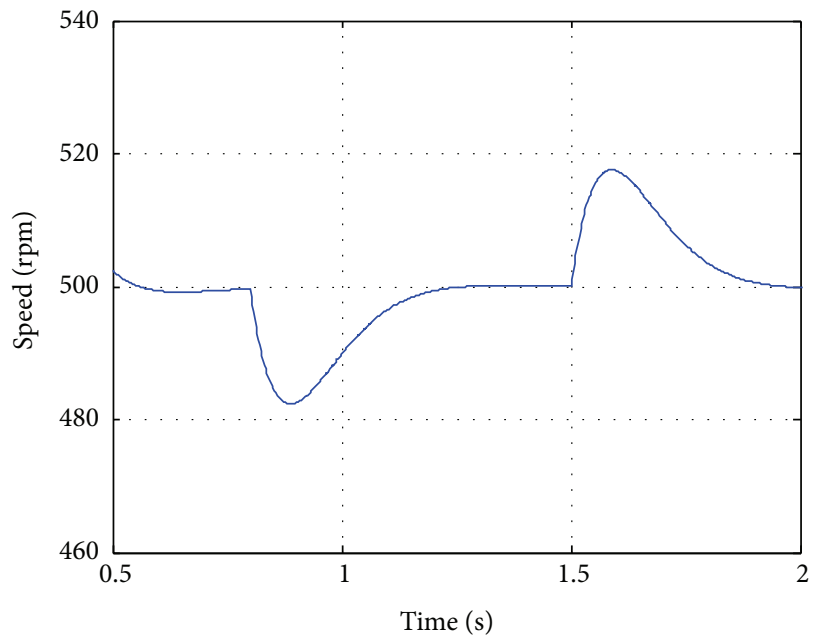

(a)

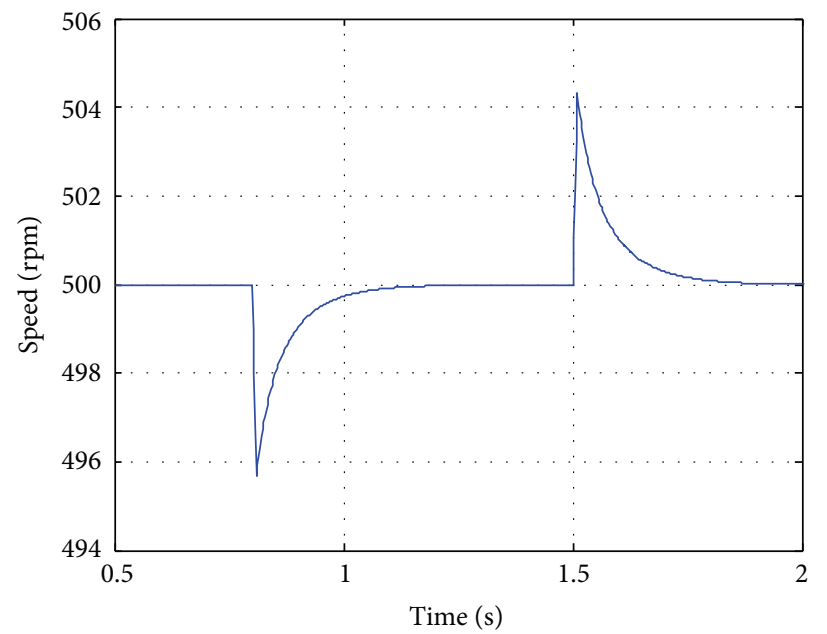

(c)

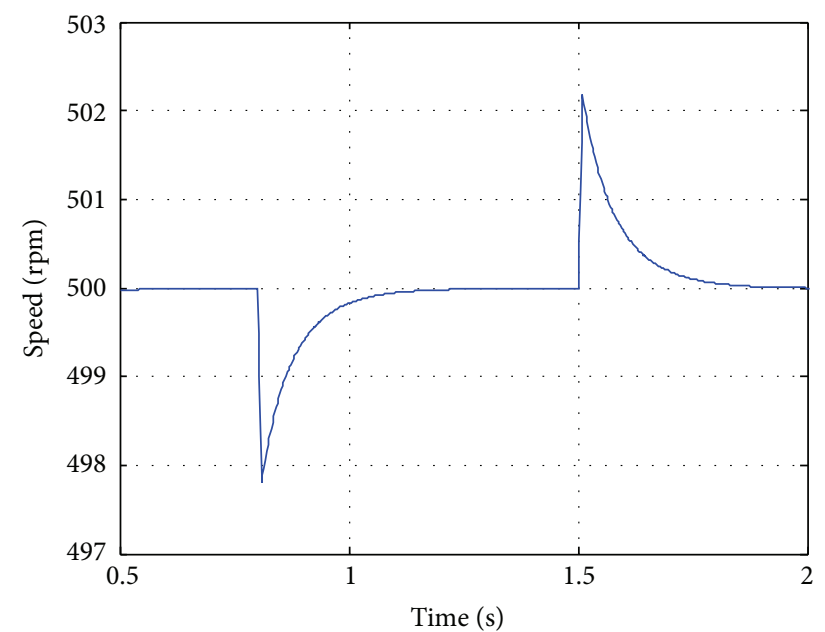

(b)

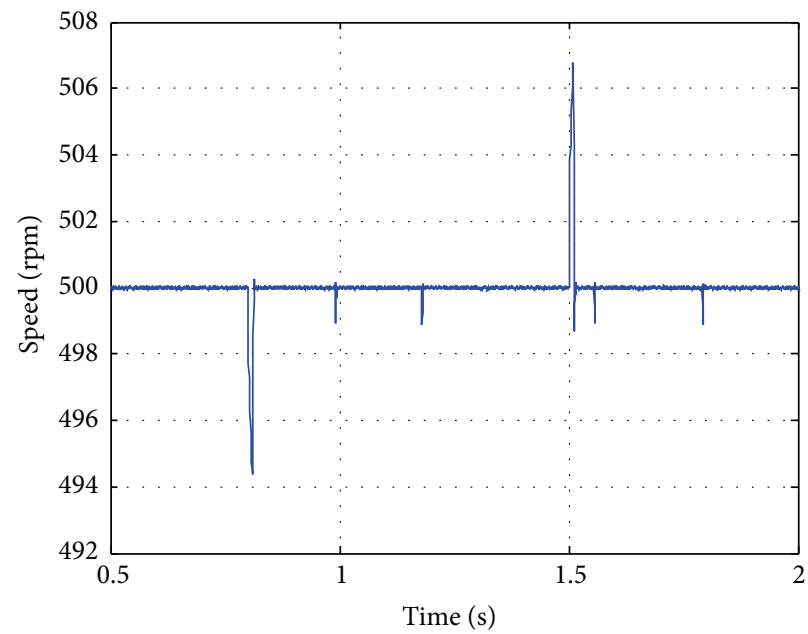

(d)

FIGURE 8: Speed variations of (a) PI controller, (b) ESMRL + ESO controller, (c) ESMRL controller, and (d) SMC controller.

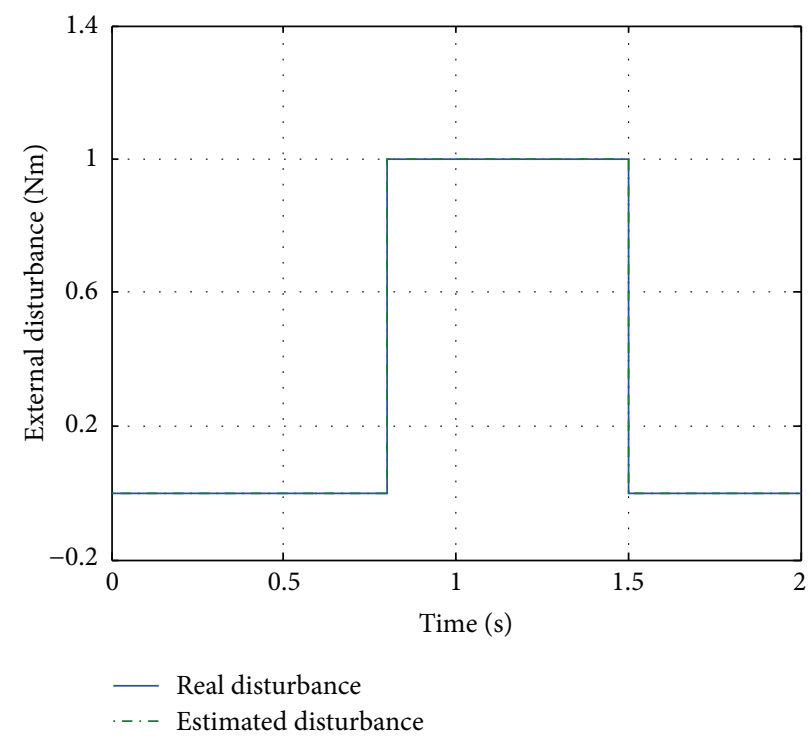

FIGURE 9: Estimated disturbance of ESO. 


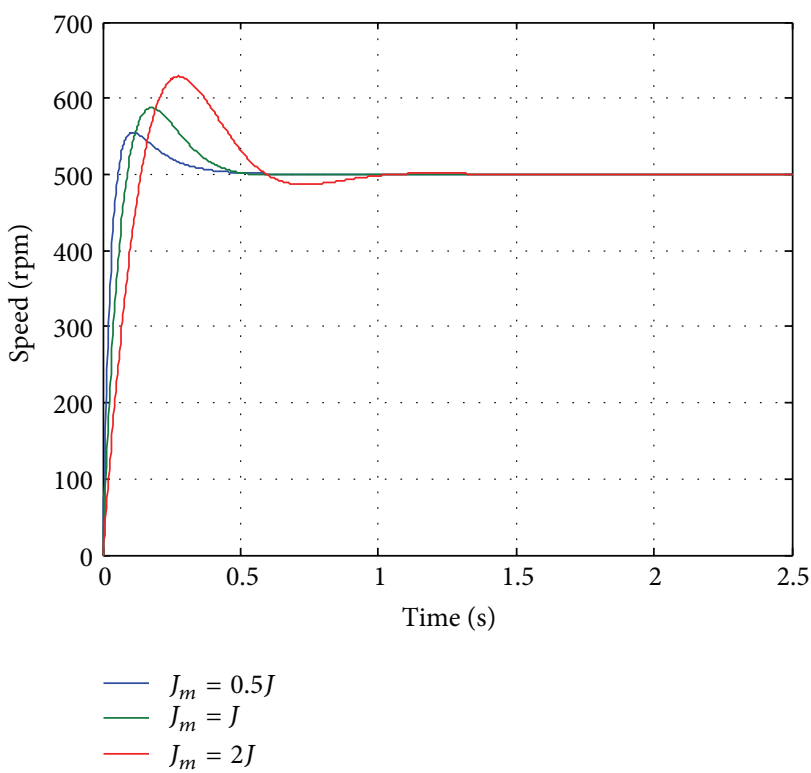

(a)

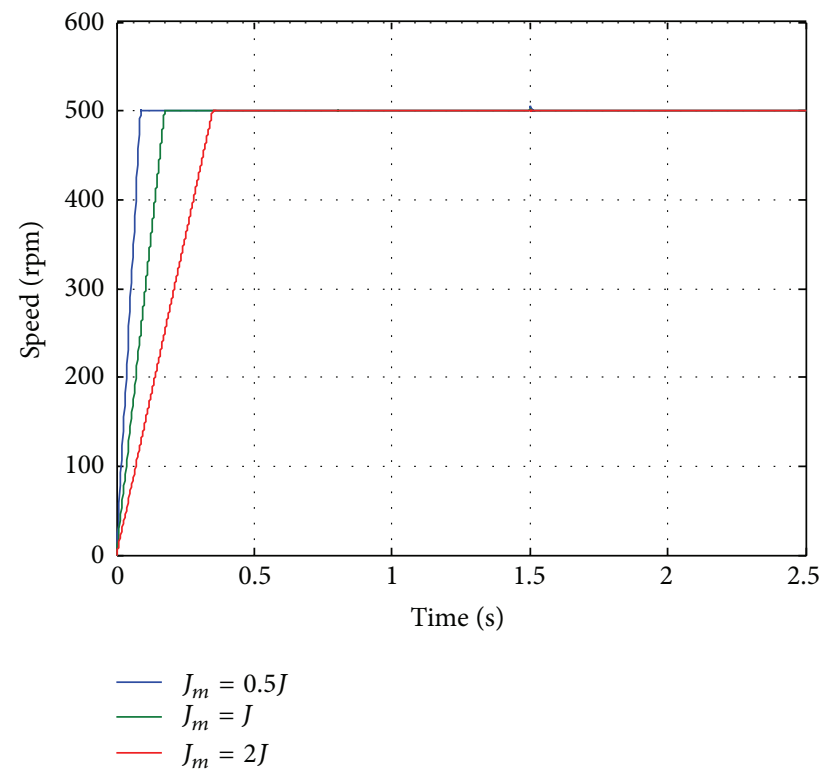

(b)

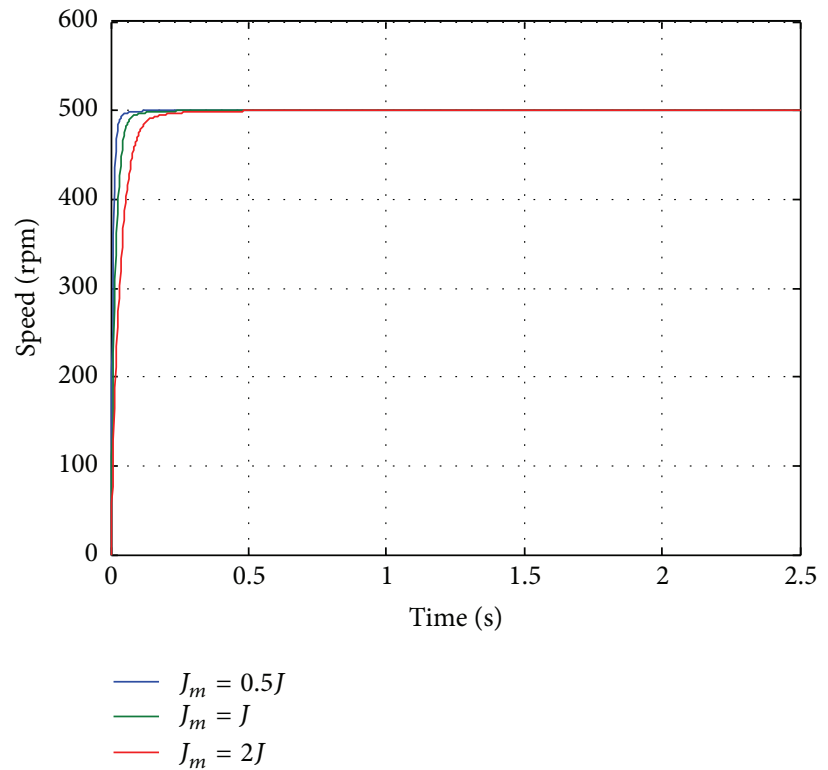

(c)

FIGURE 10: Speed response with different inertia: (a) PI controller, (b) SMC controller, and (c) ESMRL + ESO controller.

\section{Competing Interests}

The authors declare that there is no conflict of interests regarding the publication of this paper.

\section{References}

[1] P. Pillay and R. Krishnan, "Control characteristics and speed controller design for a high performance permanent magnet synchronous motor drive," IEEE Transactions on Power Electronics, vol. 5, no. 2, pp. 151-159, 1989.

[2] O. Kaynak, K. Erbatur, and M. Ertugrul, "The fusion of computationally intelligent methodologies and sliding-mode control-a survey," IEEE Transactions on Industrial Electronics, vol. 48, no. 1, pp. 4-17, 2001.

[3] B. Grcar, P. Cafuta, and M. Znidaric, "Nonlinear control of synchronous servo drive," in Proceedings of the International Conference on Control, vol. 2, pp. 1198-1203, March 1994.

[4] J. Han, "From PID to active disturbance rejection control," IEEE Transactions on Industrial Electronics, vol. 56, no. 3, pp. 900906, 2009.

[5] C.-K. Lai and K.-K. Shyu, "A novel motor drive design for incremental motion system via sliding-mode control method," IEEE Transactions on Industrial Electronics, vol. 52, no. 2, pp. 499-507, 2005.

[6] Y. Feng, J. Zheng, X. Yu, and N. V. Truong, "Hybrid terminal sliding-mode observer design method for a permanent-magnet 
synchronous motor control system," IEEE Transactions on Industrial Electronics, vol. 56, no. 9, pp. 3424-3431, 2009.

[7] R.-J. Wai, "Total sliding-mode controller for PM synchronous servo motor drive using recurrent fuzzy neural network," IEEE Transactions on Industrial Electronics, vol. 48, no. 5, pp. 926944, 2001.

[8] R. Errouissi and M. Ouhrouche, "Nonlinear predictive controller for a permanent magnet synchronous motor drive," Mathematics \& Computers in Simulation, vol. 81, no. 2, pp. 394406, 2010.

[9] Y.-S. Kung and M.-H. Tsai, "FPGA-based speed control IC for PMSM drive with adaptive fuzzy control," IEEE Transactions on Power Electronics, vol. 22, no. 6, pp. 2476-2486, 2007.

[10] S. Tong and H.-X. Li, "Fuzzy adaptive sliding-mode control for MIMO nonlinear systems," IEEE Transactions on Fuzzy Systems, vol. 11, no. 3, pp. 354-360, 2003.

[11] F.-J. Lin and R.-J. Wai, "Adaptive and fuzzy neural network sliding-mode controllers for motor-quick-return servomechanism," Mechatronics, vol. 13, no. 5, pp. 477-506, 2003.

[12] R.-J. Wai and H.-H. Chang, "Backstepping wavelet neural network control for indirect field-oriented induction motor drive," IEEE Transactions on Neural Networks, vol. 15, no. 2, pp. 367-382, 2004.

[13] J. Yu, B. Chen, H. Yu, and J. Gao, "Adaptive fuzzy tracking control for the chaotic permanent magnet synchronous motor drive system via backstepping," Nonlinear Analysis: Real World Applications, vol. 12, no. 1, pp. 671-681, 2011.

[14] S. Tong and Y. Li, "Observer-based fuzzy adaptive control for strict-feedback nonlinear systems," Fuzzy Sets and Systems, vol. 160, no. 12, pp. 1749-1764, 2009.

[15] O. Camacho and C. A. Smith, "Sliding mode control: an approach to regulate nonlinear chemical processes," ISA Transactions, vol. 39, no. 2, pp. 205-218, 2000.

[16] A. R. Ghafari-Kashani, J. Faiz, and M. J. Yazdanpanah, "Integration of non-linear $H_{\infty}$ and sliding mode control techniques for motion control of a permanent magnet synchronous motor," IET Electric Power Applications, vol. 4, no. 4, pp. 267-280, 2010.

[17] G. Foo and M. F. Rahman, "Sensorless sliding-mode MTPA control of an IPM synchronous motor drive using a slidingmode observer and HF signal injection," IEEE Transactions on Industrial Electronics, vol. 57, no. 4, pp. 1270-1278, 2010.

[18] J.-J. E. Slotine and S. S. Sastry, "Tracking control of nonlinear systems using sliding surfaces, with application to robot manipulators," International Journal of Control, vol. 38, no. 2, pp. 465-492, 1983.

[19] A. Kawamura, H. Itoh, and K. Sakamoto, "Chattering reduction of disturbance observer based sliding mode control," IEEE Transactions on Industry Applications, vol. 30, no. 2, pp. 456461, 1994.

[20] G. Bartolini, A. Pisano, and E. Usai, "On the second-order sliding mode control of nonlinear systems with uncertain control direction," Automatica, vol. 45, no. 12, pp. 2982-2985, 2009.

[21] W. Gao and J. C. Hung, "Variable structure control of nonlinear systems. A new approach," IEEE Transactions on Industrial Electronics, vol. 40, no. 1, pp. 45-55, 1993.

[22] J. Q. Han, "A class of extended state observers for uncertain systems," Control \& Decision, vol. 10, no. 1, pp. 85-88, 1995.

[23] B. Sun and Z. Gao, "A DSP-based active disturbance rejection control design for a 1-kW H-bridge DC-DC power converter," IEEE Transactions on Industrial Electronics, vol. 52, no. 5, pp. 1271-1277, 2005. 


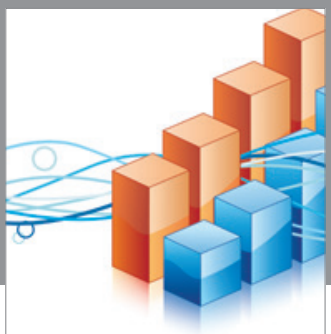

Advances in

Operations Research

vatem alat4

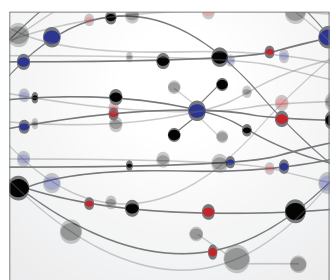

\section{The Scientific} World Journal
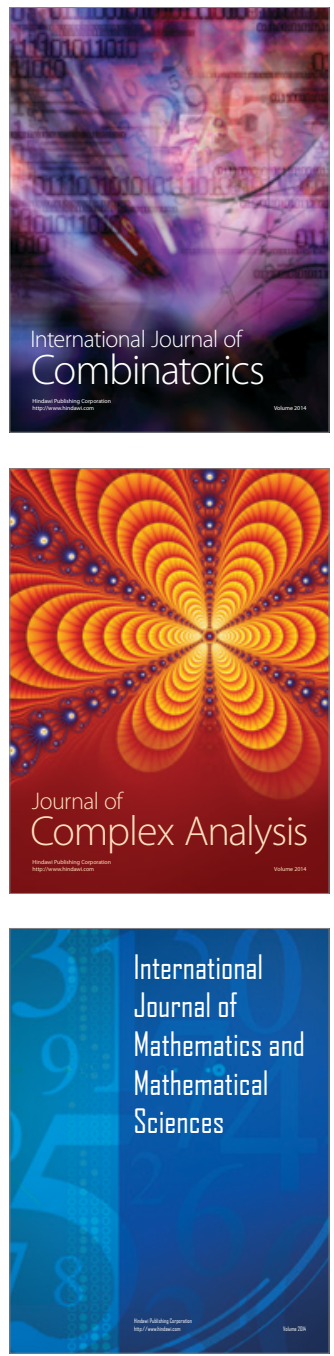
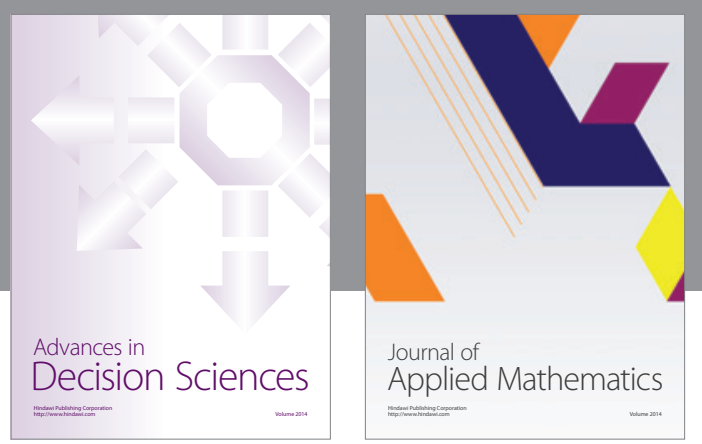

Algebra

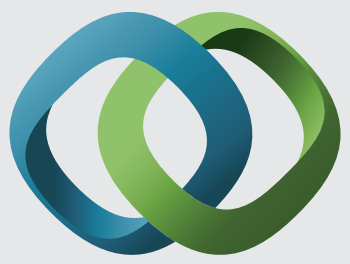

\section{Hindawi}

Submit your manuscripts at

http://www.hindawi.com
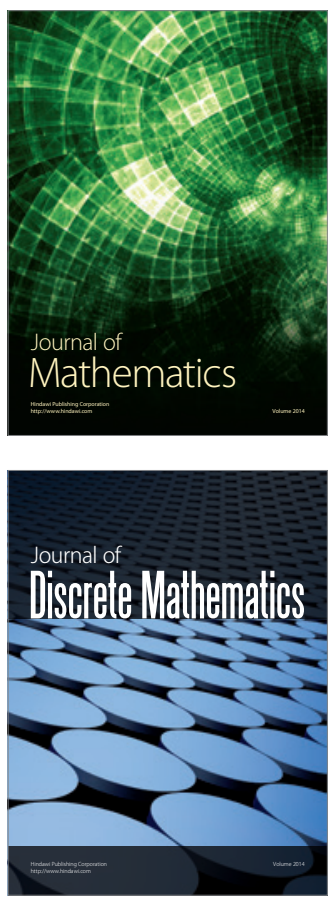

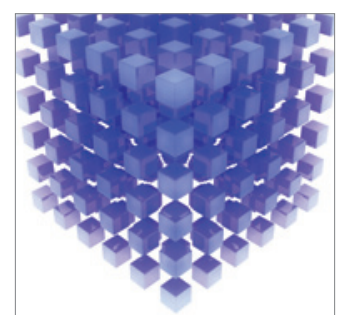

Mathematical Problems in Engineering
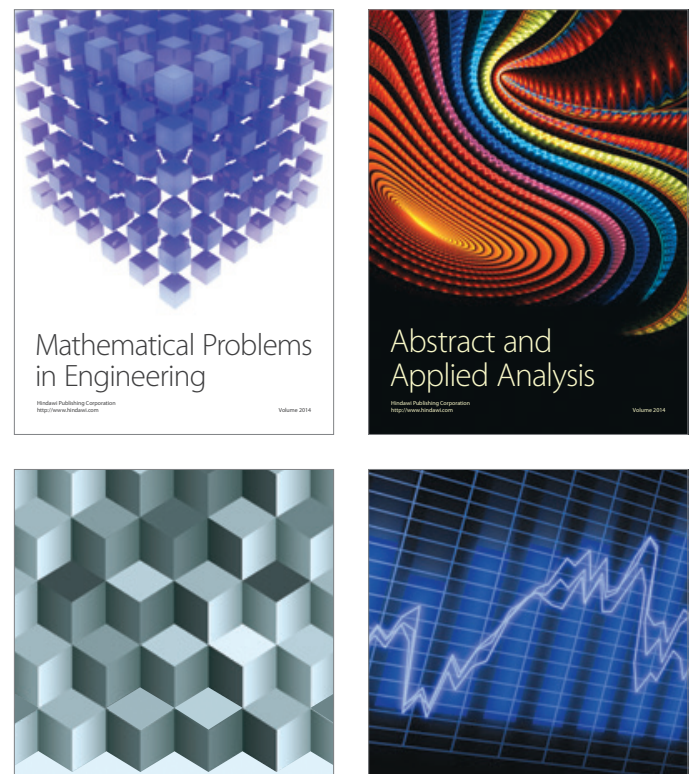

Journal of

Function Spaces

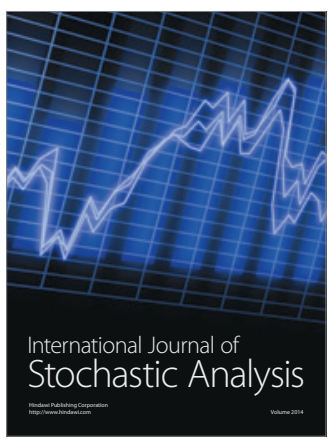

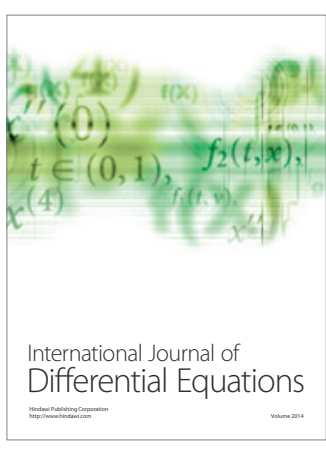
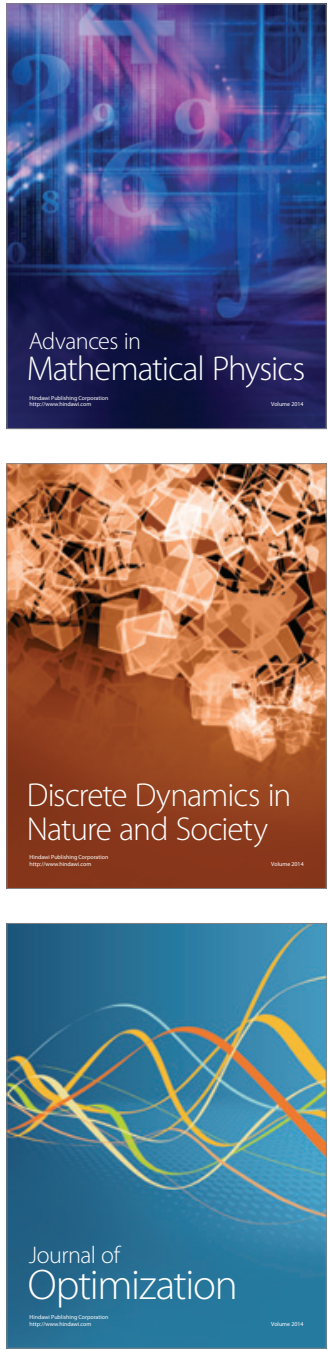